\title{
Attendee Profile of a Clubfoot Patient: Experiences from an Indian Ponseti Clubfoot Clinic
}

\author{
Vimal Kumar $\mathrm{KH}^{1}$, Anil Agarwal², Obanglemla Imsong ${ }^{3}$
}

\begin{abstract}
Introduction: The attendee (relatives) profile of clubfoot child for initiating treatment is probably a gross measure of family responsibility and social awareness regarding the disease in Indian circumstances. We conducted a prospective pilot study with primary research question "Who brings the clubfeet patient to the clubfeet clinic?" Further, the patients were followed up to 7 visits to see any gross changes in the attendee trend. The involvement of second-degree relatives was also closely monitored.

Materials and methods: The CURE counselors recorded the relatives accompanying the newly enrolled clubfoot patients (July-December 2017). Patients already in follow-up, with irregular follow-up, lost to follow-up, and not willing to participate in the study were excluded. For the purpose of statistical analysis, the total opportunities to accompany patient (100 patients $\times 7$ visits $=700$ occasions) were taken as the base measurement. Results: Out of 100 studied patients, only 39 children sought treatment within 6 weeks. Mother accompanied the child most (88.5\%) followed by father $(71.7 \%)(p<0.000001)$. Both parents accompanied the child on $62.4 \%$ occasions. The second-degree relatives accompanied the child on $32.7 \%$ occasions $(p<0.000001)$. The most persistent attendee over 7 weeks was child's mother, followed by father and next by parents together. The second-degrees relatives were least persistent of all.

Conclusion: Our study showed a high percentage of parental participation and its persistence during the casting phase of Ponseti method in Indian clubfoot children. There seems to be a lot of scope for further community education and awareness in view of the relatively older child being brought for treatment and lesser involvement of second-degree relatives.

Keywords: Attendee, Clubfoot, CTEV.

Journal of Foot and Ankle Surgery (Asia-Pacific) (2019): 10.5005/jp-journals-10040-1098
\end{abstract}

\section{INTRODUCTION}

Clubfoot is one of the most common congenital birth defect. There is published literature on the caregivers of clubfoot children regarding their perceived etiopathology of clubfoot, barriers to treatment faced, psychological effect of disease on them, etc. ${ }^{1-4}$ These studies also point out that clubfoot still has significant social stigma attached to it, Indian subcontinent being no exception. ${ }^{1}$ The clubfoot child may additionally face social and family neglect. For the same reasons, the clubfoot child's treatment is usually considered a mother's responsibility. ${ }^{2,4}$

The National and State Indian governments kick-started Ponseti clubfoot clinics in various government institutions on a unique public-private partnership model from 2009. There has been significant focus on doctor's training and public awareness in the above program in addition to the treatment of the child with clubfeet in a dedicated clinic setup. A frank evaluation of social impact of clubfoot program is presently unavailable. The attendee (relatives) profile of the clubfoot child, newly enrolled for initiating treatment, is probably a gross measure of family responsibility and social awareness regarding the disease in Indian circumstances. We therefore conducted a prospective pilot study with primary research question "Who brings the clubfeet patient to the Clubfeet clinic?" Further, the patients were followed up to seven visits to see any changes in the attendee trend. The involvement of seconddegree relatives was also closely monitored.

\section{Materials and Methods}

This prospective study was conducted at a Clubfoot Clinic at a pediatric super specialty center located in suburb of capital city,

\author{
${ }^{1-3}$ Department of Pediatric Orthopedics, Chacha Nehru Bal \\ Chikitsalaya, Delhi, India
}

Corresponding Author: Anil Agarwal, Department of Pediatric Orthopedics, Chacha Nehru Bal Chikitsalaya, Delhi, India, Phone: +91 9810290295, e-mail: rachna_anila@yahoo.co.in

How to cite this article: Vimal Kumar KH, Agarwal A, et al. Attendee Profile of a Clubfoot Patient: Experiences from an Indian Ponseti Clubfoot Clinic. J Foot Ankle Surg (Asia-Pacific) 2019;6(1):7-9.

\section{Source of support: Nil}

Conflict of interest: None

Delhi (India). The counselors observed and recorded the relatives accompanying the clubfoot patient from their first enrolment at the clinic to seven subsequent visits (July-December 2017). The seven visit criteria were based on the average number of casts required for treatment of clubfoot before brace prescription. Patients already in follow-up, with irregular follow-up, and lost to follow-up were excluded. A total of 103 consecutive new patients were initially selected for the study; three cases were later excluded from calculations as the follow-up for them was just for 5 weeks. A full and free consent was obtained from patients' relatives for the study to be published, to which they did not have any objection.

The data were recorded on an Excel sheet. The relatives were grouped into two broad categories-first-degree (mother and father) and second-degree relatives (all others). For the purpose of statistical analysis, the total opportunities to accompany patient (100 patients $\times 7$ visits $=700$ occasions) were taken as the base measurement and the relatives' attendance was matched with

() The Author(s). 2019 Open Access This article is distributed under the terms of the Creative Commons Attribution 4.0 International License (https://creativecommons. org/licenses/by-nc/4.0/), which permits unrestricted use, distribution, and non-commercial reproduction in any medium, provided you give appropriate credit to the original author(s) and the source, provide a link to the Creative Commons license, and indicate if changes were made. The Creative Commons Public Domain Dedication waiver (http://creativecommons.org/publicdomain/zero/1.0/) applies to the data made available in this article, unless otherwise stated. 


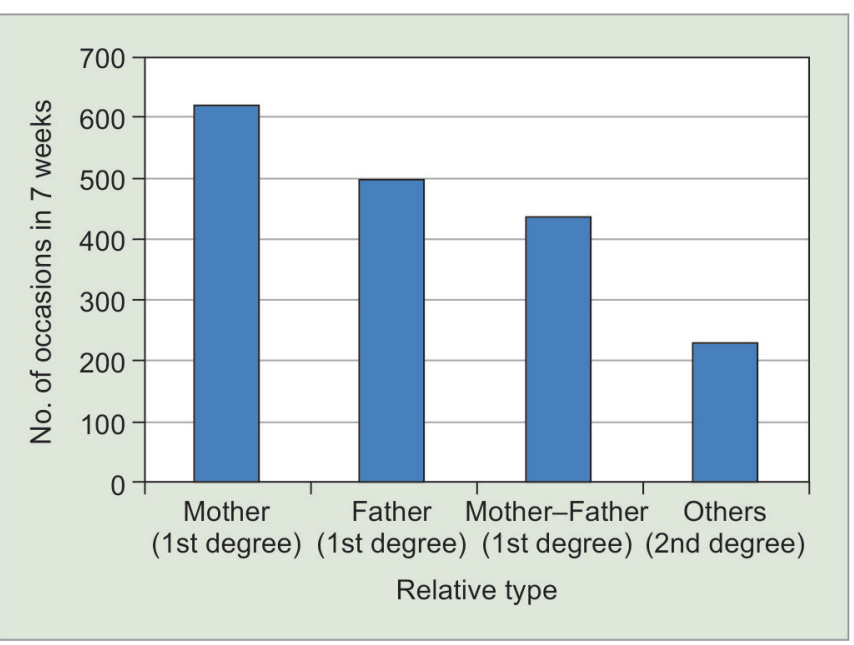

Fig. 1: Distribution of relatives over the 700 occasions available

this. The paired nominal data with dichotomous trait (first-degree relatives) was analyzed by McNemar's test (http://vassarstats.net).

\section{Results}

Out of 100 patients, only 39 children sought an early treatment within 6 weeks (39\%). The male-female ratio was 17:8. The relative who accompanied the child most to the clinic was mother, $(620 / 700)$ $88.5 \%$, followed by father, (502/700) 71.7\% (Figs 1 and 2). Both mother and father accompanied the child together on (437/700) $62.4 \%$ occasions. The second-degree relatives (grandmother, grandfather, mother's sister, mother's brother, uncle, aunty, mother in law) accompanied the child on (229/700) $32.7 \%$ occasions. There was a significant difference between mother and father $(p<0.000001)$ as well as first- and second-degree relative attendance $(p<0.000001)$.

On most occasions, two relatives accompanied the child, $(616 / 700) 88 \%$, the cohort being dominated by child's parents, (437/700) $62.4 \%$. Three relatives accompanied the child on lesser occasions, 8.1\% (57/700).

The most persistent attendee over all 7 weeks was child's mother, 81/100 (81\%), followed by father, 62/100 (62\%) (Fig. 3). Both parents were present for $57 / 100$ (57\%) patients all weeks. The second-degree relatives were constant only for $16 / 100(16 \%)$ children.

\section{Discussion}

Clubfoot over the ages has been considered a social stigma leading to societal isolation of the child as well as their families. ${ }^{2}$ Lack of awareness, poverty, difficult access to health care facilities, and unavailability of proper treatment are other factors responsible for delay in seeking treatment and disability resulting from clubfoot. National and regional Indian governments introduced the Ponseti method of clubfoot treatment in 2009 under a public-private partnership model. Over a period of 8 years, over 27,000 children have been enrolled in this nationwide Indian clubfoot initiative spread across 35 states and union territories through 200 designated clubfoot clinics. ${ }^{5}$ Besides clinics, the program also involves doctor's training, counselor support for clubfoot patient, educating ASHA workers under the National Rural Health Mission (NHRM) and the Rashtriya Bal Swasthya Karyakram (RBSK), and raising community awareness through public campaigns and home visits. Although the sheer numbers of patients enrolled show the program's impact,

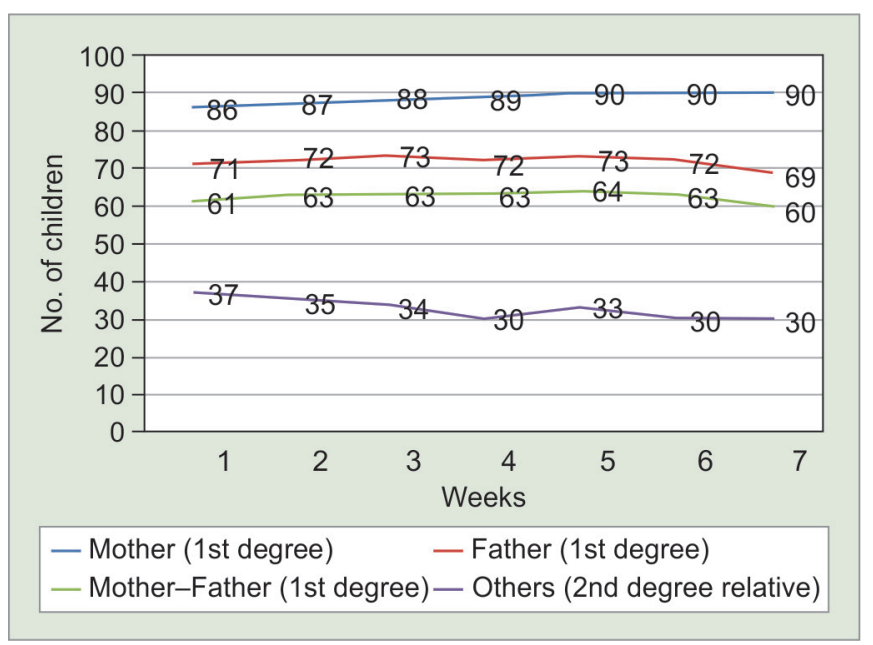

Fig. 2: Trend of relative attendance over a 7-week period

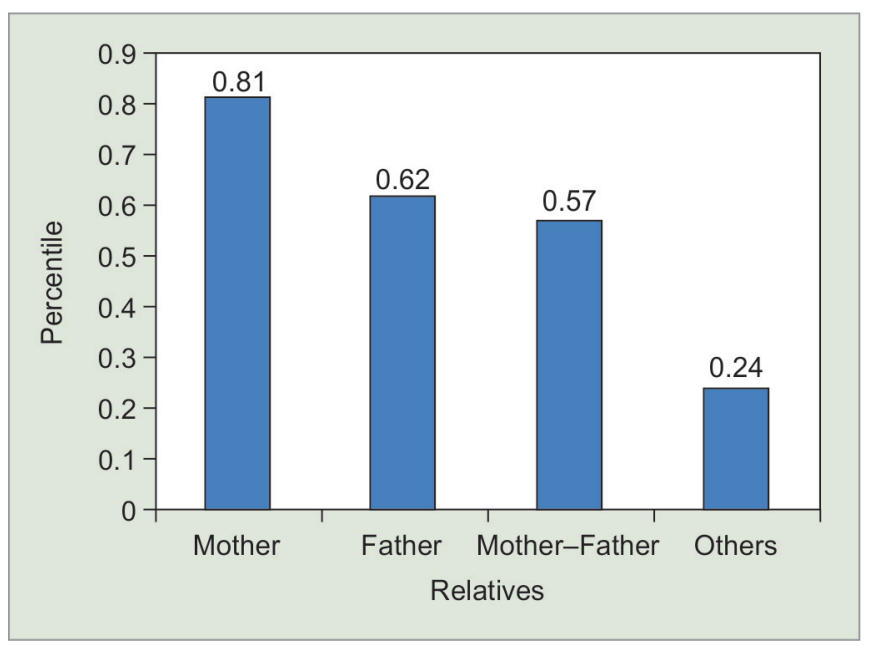

Fig. 3: Persistence of relatives over a 7-week period

the family participation and societal influence largely remain unevaluated.

Our study showed a low percentage (39\%) of patients being brought before the age of 6 weeks. Another Indian study conducted in 2014 showed that $42 \%$ clubfoot patients were under 6 weeks of age when first enrolled for treatment. ${ }^{6}$ This clearly does not match with international recommendation of introducing Ponseti treatment soon after birth. The male-female ratio in our study was similar to that reported in world literature. ${ }^{7}$

The high percentage of maternal involvement (88.5\%) and persistence over the 7-week period is clearly understandable. Social responsibility of the child's health, concerns of infant's feeding and general requirements, post casting care, etc. are some of the factors guiding maternal presence at the clubfoot clinic. Previous studies originating from other world regions have also marked females/ mothers as primary attendees for clubfoot patients (63-98\%). ${ }^{2,3} \mathrm{We}$ believe that the small percentage of percentage of patients where mother could not attend the clinic was possibly because of her own health reasons (cesarean section, etc.) or social/family restrictions after child's birth practiced in certain sects of the Indian society.

Lack of paternal support has been identified as a barrier to successful treatment with the Ponseti method. ${ }^{1}$ A high paternal attendance $(71.7 \%)$ in our study, although significantly less than maternal, was a positive and applaudable observation. These 
numbers contrasted sharply with those quoted in literature from African countries (2\%). ${ }^{3}$ The presence of both parents at clinic is reported only from China. ${ }^{4}$ Being a partner to mother in health needs of the child indicates the changing attitude of Indian family regarding clubfoot. The stigma of child born with clubfoot as a social shame and untreatable is slowly being dispensed with by both Indian parents. The availability of health care facilities and clubfoot clinics in close vicinity are thus making a positive impact. The parents seemed motivated enough to complete the clubfoot treatment as we found just three children drop out over 7 weeks in the initially enrolled 103 children. This was also quite visible in parent's determined attendance over 7 weeks both individually (mother $81 \%$; father 62\%) and together (57\%).

The number of second-degree relatives attending clinics (32.7\%) was relatively less compared to first-degree relatives. This may not be taken in a negative sense as already two attendees accompanied child (parents together $62.4 \%$ ) or one of the seconddegree relatives accompanied mother or father $(25.7 \%)$ on other occasions. Further, the parents of the child were in better position to take care of the child (esp. feeding) than possibly a seconddegree relative. However, the findings of our study suggest further strengthening of the awareness among them.

Our study had limitations on small sample size, recording of patient's attendees without consideration of their religion, income, education, health, or family circumstances. The distance travelled to the health care facility, prior treatment sought, and attendance at further follow-up were not documented. Additionally, being a hospital-based study, it may have possible differences from overall societal trends. Our study showed a high percentage of parental participation and its persistence during the casting phase of Ponseti method in Indian clubfoot children. If the parental participation is considered a proxy marker of family involvement, Indian parents showed a positive uptrend (62\%) compared to other world societies. There seems to be a lot of scope for further community education and awareness in view of the relatively older child being brought for treatment and lesser involvement of second-degree relatives.

\section{References}

1. Gadhok K, Belthur MV, et al. Qualitative assessment of the challenges to the treatment of idiopathic clubfoot by the Ponseti method in urban India. lowa Orthop J 2012;32:135-140.

2. Botchway $\mathrm{H}$, Belinda $\mathrm{A}$, et al. Parents/caregivers perception about the management of clubfoot: the case of St. John of God Hospital. Intl Jrnl of Innovative Research in Edu Tech and Social Strategies 2016;2:85-94.

3. Kazibwe H, Struthers P. Barriers experienced by parents of children with clubfoot deformity attending specialised clinics in Uganda. Trop Doct 2009;39:15-18. DOI: 10.1258/td.2008.080178.

4. Lu N, Zhao L, et al. From cutting to casting: impact and initial barriers to the Ponseti method of clubfoot treatment in China. lowa Orthop J 2010;30:1-6.

5. History of CURE-Club Foot India (2016), http://clubfootindia.in/ about-us/, (assessed September 24, 2017).

6. Sharma P, Verma R, et al. Analysis of the effectiveness of a nongovernmental organization in supporting clubfoot clinic at a tertiary care center. SICOT J 2015;1:8. DOI: 10.1051/sicotj/2015008.

7. Wynne-Davies R. Family studies and the cause of congenital club foot talipes equinovarus, talipes calcaneo-valgus and metatarsus varus. J Bone Joint Surg Br 1964;46:445-463. DOI: 10.1302/0301620X.46B3.445. 